\title{
Application of the Enterprise Stent in Atherosclerotic Intracranial Arterial Stenosis: A Series of 60 Cases
}

\author{
Xiaofei WANG ${ }^{1}$, Zhigang WANG ${ }^{2}$, Chengwei WANG ${ }^{1}$, Yong $\mathrm{JI}^{1}$, Xuan DING ${ }^{1}$, Yizheng ZANG ${ }^{1}$ \\ ${ }^{1}$ Shandong University, The Second Hospital, Department of Neurosurgery, Jinan 250003, Shandong, China \\ 2Shandong University, Qilu Hospital, Department of Neurosurgery, Qingdao 266071, Shandong, China
}

\section{ABSTRACT}

AIM: We assessed the safety and effectiveness of the Enterprise stent in treating atherosclerotic intracranial arterial stenosis (AIAS).

MATERIAL and METHODS: This was a retrospective study conducted with 60 consecutive patients with 62 AIAS lesions who received the Enterprise stent at the Department of Neurosurgery, Second Hospital of Shandong University between June 2012 and January 2014. All patients were assessed using the modified Rankin scoring system at discharge. Clinical follow-ups and digital subtraction angiography (DSA) were performed at 1, 3, 6 and 12 months postoperatively.

RESULTS: There were 42 men and 18 women with a mean age of $56.8 \pm 8.0$ years. Fourteen lesions (22.6\%) were at the anterior and $48(77.4 \%)$ were at the posterior circulation. The mean stenosis rate was $76.3 \pm 12.7 \%$. The mean stenotic vessel length was $7.7 \pm 2.0 \mathrm{~mm}$. The technical success rate was $100 \%$. The mean post-stent residual stenosis rate was $22.8 \pm 4.8 \%$. Five patients (8.3\%) had perioperative complications, but no disability or mortality occurred within 30 days. The mean follow-up duration was 6.2 months. DSA was used to evaluate 45 lesions (72.6\%) six months postoperatively: 6 (13.3\%) had postoperative restenoses, 2 at the anterior circulation, and 4 at the posterior circulation. Of these $6,4(66.7 \%)$ were immediate residual stenoses after stenting. The residual stenosis rate was identified as a risk factor for restenosis. Five (8.3\%) ischemic events, consistent with the vascular lesions, occurred.

CONCLUSION: Application of the Enterprise stent was safe and efficacious. The technical success rate was high while the perioperative complication rate was low.

KEYWORDS: Enterprise stent, Atherosclerosis, Endovascular procedures, Carotid stenosis, Basilar artery stenosis, Cerebral arteries

\section{INTRODUCTION}

Interventional treatments for atherosclerotic intracranial arterial stenosis (AIAS) have been introduced more than a decade ago, and have evolved from balloon angioplasty to balloon angioplasty with stenting to self-expanding stenting. At present, there are two main types of stents for intracranial stenosis: the balloon-expandable stent and the self-expanding stent. Compared with balloon-expandable stents, self-expanding stents have better flexibility for an easier approach to the target vessels, a hydrophilic coating to reduce intimal injuries, and a sub-satisfactory balloon dilation to decrease the risk of vascular rupture (9). Park et al (19) found in their controlled study on the comparison of intracranial self-expanding and balloon-expandable stents that both stent types could improve prognosis, but adverse events with the self-expanding stent were significantly lower than with the balloon expandable stent.

The Wingspan system was the earliest intracranial selfexpanding stent used clinically. Developed by Boston Scientific Corporation, the Wingspan stent adopts a Gateway balloon with a slightly smaller diameter than the target vessel to perform sub-satisfactory dilation and then implants a self- 
expanding stent with a slightly larger diameter than the target vessel. Early clinical studies revealed that Wingspan stenting was safe during the perioperative period while maintaining a high technical success rate (3). However, a recent large-scale multi-center study in high-risk patients with intracranial artery stenosis (SAMMPRIS) reached a different conclusion (5). That study was terminated because the incidence of stroke and death in the Wingspan stent group within 30 days was significantly higher than those of the control group, and the adverse events in the Wingspan stent group were twice as many than expected (2). Some researchers believed that the high radial strength of the Wingspan stent might be one of the reasons for the high postoperative restenosis rate (24).

The Enterprise stent was designed as an adjuvant stent for embolization of intracranial aneurysms and has been widely used for that procedure $(10-12,14,17,20)$. As a self-expanding stent similar to the Wingspan stent, the Enterprise stent is a closed-loop stent with a different design compared with the Wingspan stent (Figure 1A-C). Krischek et al (15) conducted an in vitro study comparing the functional and physical properties of self-expanding intracranial stents and the results indicated that, compared with the Wingspan stent, the Enterprise stent has less radial strength and better flexibility and transportability, which enable more precise positioning and release. After SAMMPRIS, a study has investigated the use of the Enterprise stent in AIAS, and showed that the Enterprise stent was safe and effective to treat AIAS (24).

The aim of the present study was to assess the safety and efficacy of the Enterprise stent in treating AIAS in a Chinese patient population. This should provide additional information for the use of the Enterprise stent for AIAS in selected patients.

\section{MATERIAL and METHODS}

\section{Patients}

This was a retrospective study conducted with 60 patients with 62 lesions admitted to the Neurosurgery Department of the Second Hospital of Shandong University between June 2012 and January 2014 and treated using Enterprise stents (Codman, US). These patients were consecutively admitted and newly diagnosed. Diagnosis was confirmed by digital subtraction angiography (DSA).

In our hospital, patients found with symptomatic AIAS are initially treated with aspirin $300 \mathrm{mg}$ qd (or $100 \mathrm{mg}$ qd for patients with tendency to bleed with medication), Plavix 75 $\mathrm{mg}$ qd, and atorvastatin $20 \mathrm{mg}$ qn. If the symptoms remain, they become eligible for stenting. Patients experiencing a second transient ischemic attack (TIA) or minor stroke during medication are immediately eligible for stenting. Additional eligibility criteria for stenting were: 1) symptomatic intracranial arterial stenoses with symptoms consistent with the vascular lesions in the blood-supplied regions; 2) cerebral artery with a stenosis rate $\geq 50 \%$ with an inadequate perfusion confirmed by computed tomography (CT) and magnetic resonance (MR) perfusion-weighted imaging; 3) stenotic sites located at the internal carotid artery, M1 segment of the middle cerebral artery, intracranial vertebral artery or basilar artery, and the feasibility of implantation of balloons and stents was predicted operatively; and 4) patients with a modified Rankin score $(\mathrm{mRS})$ of $\leq 3$ points.

Exclusion criteria were: 1) non-atherosclerotic (arteritis, or induced by other factors such as the moyamoya disease) intracranial arterial stenosis; 2) arterial dissection; or 3) acute cerebral infarction within two weeks.

This study was approved by the Ethical Committee of the Second Hospital of Shandong University. All patients involved in the study signed an informed consent preoperatively.

\section{Study Design}

Preoperative MR and CT imaging (Siemens, Erlangen, Germany) and routine neurological examinations were performed. Patients were prescribed clopidogrel $75 \mathrm{mg} / \mathrm{d}$ and aspirin $300 \mathrm{mg} / \mathrm{d}$ (or $100 \mathrm{mg}$ qd for patients with tendencies to bleeding) at least 3 days preoperatively. Patients had to have a systolic blood pressure $<160 \mathrm{mmHg}$ before operation. Patients received $20 \mathrm{mg}$ of nimodipine in $100 \mathrm{ml}$ administered over $24 \mathrm{~h}$ by pumping to avoid the occurrence of vasospasms. Routine general anesthesia and heparinization were performed intraoperatively.

Using the Innova $3100 \mathrm{IQ}$ digital flat-panel angiography instrument (GE Healthcare, Buckinghamshire, UK), cerebral

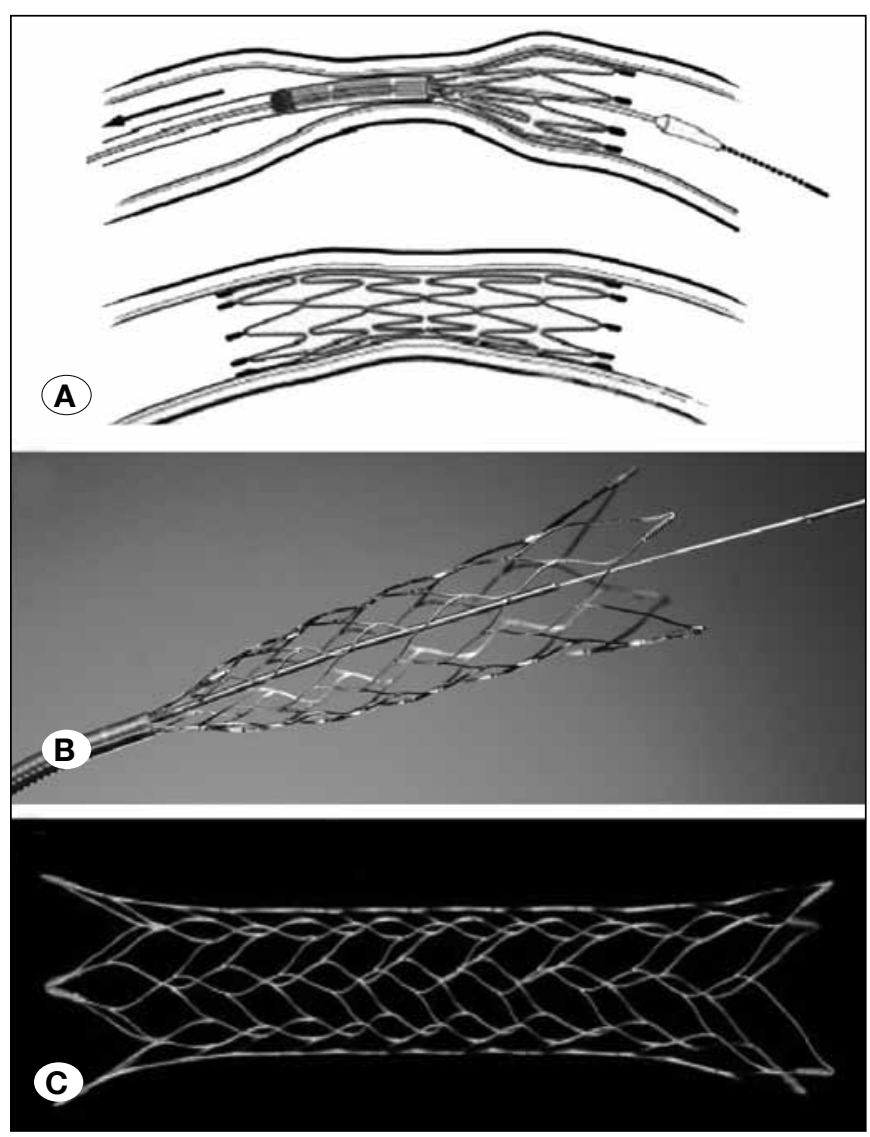

Figure 1: Images of the Wingspan and Enterprise stents. A)Wingspan stent with open-loop design. B, C) Enterprise stent with closed-loop design. 
angiography was performed prior to the treatments. The size of the Gateway balloon was selected as $80 \%$ of the diameter of the vessel that was proximal to the stenosis. The balloon was dilated slowly, with a final pressure of 607.950-1013.250 $\mathrm{kPa}(6-10 \mathrm{~atm})$ for 30 seconds. The stent diameter was $1.5 \mathrm{~mm}$ wider than that of the target vessel, and the exceeding length of the stent was at least $3 \mathrm{~mm}$ longer than that of the target lesion. The stent was placed using standard techniques. The surgery was terminated if angiography performed immediately after stenting showed that all the stents were patent without thrombosis or perforating artery occlusion. All the surgeries were performed by the director of the Neurosurgery department (more than 20 years expertise in neurological interventional treatments).

The postoperative systolic blood pressure was maintained at $<120 \mathrm{mmHg}$. For postoperative medications, aspirin 300 $\mathrm{mg} / \mathrm{d}$ (or $100 \mathrm{mg} / \mathrm{d}$ for patients with tendency to bleed) was prescribed for the first month and the dose was adjusted to $100 \mathrm{mg} / \mathrm{d}$ from the second month and maintained for life. Clopidogrel $75 \mathrm{mg} / \mathrm{d}$ was prescribed for 3 months. If ischemic events appeared, another 6 months of clopidogrel was given.

\section{Clinical Data Collection and Examination}

The observations indices included patient age, sex, symptoms, stenotic site, diameter of the normal vessel proximal to the stenosis, stenotic degree, stenotic length, Mori classification, models of the balloons and stents, post-stent residual stenosis rate, perioperative complications, modified Rankin scoring system (mRS) scores at discharge, and mortality rate within 30 days postoperatively.

Clinical follow-ups and DSA were performed at 1, 3, 6 and 12 months postoperatively. Observation indices of the followups included in-stent restenosis (ISR) rate, recurrent ischemic events and deaths of various causes. ISR was defined as a lesion with a stenosis rate greater than $50 \%$. Immediate postoperative residual stenosis was defined as a rate $\geq 30 \%$.

\section{Statistical Analysis}

Data are presented as values with percentages, means \pm SD and range, as appropriate. Statistical analysis was performed with SPSS 19.0 (IBM, Armonk, NY, USA). Univariate and multivariate analyses were performed to evaluate whether site of the lesion and rate of residual stenosis were independent risk factors for ISR. Since the sample size was small, only residual stenosis rate, stenotic length $(\geq 8 \mathrm{~mm}$ and $<8 \mathrm{~mm}$ ), and age were included in the multivariate analysis. $\mathrm{P}<0.05$ was considered statistically significant.

\section{RESULTS}

\section{Baseline Patient Characteristics}

Of the 60 AIAS patients with 62 lesions who received treatment using the Enterprise stent, $42(70 \%)$ were men and $18(30 \%)$ were women. Their mean age was $56.8 \pm 8.0$ years old (age range: $28-68$ years old). All patients had symptomatic stenoses, $38(63.3 \%)$ of which were transient ischemic attack (TIA) and $22(36.7 \%)$ were ischemic stroke.

\section{Treatment Regimen}

The details of the 62 lesions included in this study are shown in Table I. Stenting was performed within 1 week of symptom occurrence for patients with TIA and between 2 weeks and 30 days for patients with ischemic stroke. Of the 62 lesions, $14(22.6 \%)$ were located in the anterior circulation and 48 (77.4 \%) were located in the posterior circulation; 10 were in the internal carotid artery, 4 in the M1 segment of the middle cerebral artery, 20 in the intracranial vertebral artery, and 28 in the basilar artery. Seven were Mori A lesions, 48 were Mori $\mathrm{B}$ lesions and 7 were Mori $\mathrm{C}$ lesions. Sixty were type I + type II lesions, and only 2 were type III lesions (according to the classifications of location, morphology and access). Twentyfour $(38.7 \%)$ had a stenosis rate of $50-70 \%$, $38(61.3 \%)$ had a stenosis rate of $70-99 \%$, and the mean stenosis rate was $76.3 \pm 12.7 \%$. The mean stenotic vessel length was $7.7 \pm 2.0$ $\mathrm{mm}$ (length range: $4-12.3 \mathrm{~mm}$ ). The mean diameter of the proximal segment of the stenotic vessel was $2.8 \pm 0.3 \mathrm{~mm}$ (diameter range: $1.8-3.5 \mathrm{~mm}$ ). The mean post-stent residual stenosis rate was $22.8 \pm 4.8 \%$ (rate range: $15-35 \%$ ).

\section{Treatment}

The technical success rate in this study was $100 \%$. Only Gateway balloons (Boston Scientific Corporation, Marlborough, MA, USA) were used, of which 6 were $2.0 \times 9$ $\mathrm{mm}, 10$ were $2.0 \times 15 \mathrm{~mm}, 17$ were $2.25 \times 9 \mathrm{~mm}, 8$ were $2.25 \times 15 \mathrm{~mm}, 10$ were $2.5 \times 9 \mathrm{~mm}, 5$ were $2.5 \times 15 \mathrm{~mm}, 1$ was $2.75 \times 9 \mathrm{~mm}$, and 5 were $2.75 \times 15 \mathrm{~mm}$. The inflation pressure was controlled between 6 and $10 \mathrm{~atm}$. A total of 62 Enterprise stents were implanted, and 36 of them were $4.5 \times 14 \mathrm{~mm}$ and 26 were $4.5 \times 22 \mathrm{~mm}$.

\section{Complications}

Of the 60 patients, only $5(8.3 \%)$ had perioperative complications. There was one case of in-stent thrombosis: the thrombus disappeared after thrombolytic therapy with $400,000 \mathrm{U}$ of urokinase delivered by microcatheter. There was one case of in-stent dissection: the patient was asymptomatic and the dissection was found to have self-healed at the 6-month follow-up. There was one case of intraoperative vertebral artery spasm: the symptoms were relieved after topical nimotop and papaverine application. Two patients had ischemic strokes within 30 days postoperatively. The mortality rate within the 30 days was $0 \%$. Patients' mRS scores were as follows: 0 in 42 cases, 1 in 13 cases, 2 in 3 cases, and 3 in 1 case, and 4 in 1 case. The follow-up duration was between 1 and 12 months, with a mean of 6.2 months.

Six months postoperatively, 45 lesions $(72.6 \%)$ were examined by DSA, and 6 (13.3\%) lesions were confirmed to be postoperative restenoses (stenosis rate $\geq 50 \%$ ), 2 of which were anterior $(20 \%$ of the 10 anterior lesions that were followed up), and 4 of which were posterior (11.4\% of the 35 posterior lesions that were followed up). Representative cases are shown in Figures 2A-D, 3A-D, 4A-D. Figures 2A-D and $3 A-D$ show cases that had a high grade stenosis that was successfully treated and showed no restenosis. Figure 4A-D shows a case that was successfully treated for a high grade stenosis but experienced ISR. Of the 6 restenosis lesions, 
Table I: Observation Indices of the 62 Lesions in the 60 Patients

\begin{tabular}{|c|c|c|}
\hline Variable & Value & \\
\hline Age, years & $\begin{array}{l}\text { Range: } 28-68 \text { years, } \\
56.8 \pm 8.0 \text { years }\end{array}$ & \\
\hline Sex & $\begin{array}{l}\text { Male: } 42(70 \%), \\
\text { Female: } 18(30 \%)\end{array}$ & \\
\hline $\begin{array}{l}\text { Symptom before } \\
\text { the surgery }\end{array}$ & $\begin{array}{l}\text { TIA: } 38(63.3 \%) \\
\text { Ischemic stroke: } \\
22(36.7 \%)\end{array}$ & \\
\hline \multirow[t]{4}{*}{ Lesion site } & $\begin{array}{l}\text { Anterior } \\
\text { circulation } \\
14(22.6 \%)\end{array}$ & $\begin{array}{l}\text { Internal carotid } \\
\text { artery } 10 \\
(16.1 \%)\end{array}$ \\
\hline & & $\begin{array}{l}\text { Middle } \\
\text { cerebral artery } \\
4(6.5 \%)\end{array}$ \\
\hline & $\begin{array}{l}\text { Posterior } \\
\text { circulation } \\
48(77.4 \%)\end{array}$ & $\begin{array}{l}\text { Vertebral } \\
\text { artery } 20 \\
(32.3 \%) \\
\end{array}$ \\
\hline & & $\begin{array}{l}\text { Basilar artery } \\
28(45.2 \%)\end{array}$ \\
\hline Mori classification & $\begin{array}{l}\text { A: } 7 \\
\text { B: } 48 \\
\text { C: } 7\end{array}$ & \\
\hline $\begin{array}{l}\text { Size of Gateway } \\
\text { balloon }(\mathrm{mm})\end{array}$ & $\begin{array}{l}2.0 \times 9: 6(9.7 \%) \\
2.0 \times 15: 10(16.1 \%) \\
2.25 \times 9: 17(27.4 \%) \\
2.25 \times 15: 8(12.9 \%) \\
2.5 \times 9: 10(16.1 \%) \\
2.5 \times 15: 5(8.1 \%) \\
2.75 \times 9: 1(1.6 \%) \\
2.75 \times 15: 5(8.1 \%)\end{array}$ & \\
\hline LMA classification & $\begin{array}{l}\text { I+II: } 60(96.8 \%) \\
\text { III: } 2(3.2 \%)\end{array}$ & \\
\hline Stenotic degree & $\begin{array}{l}50-70 \%: 24(38.7 \%) \\
70-90 \%: 38(63.3 \%)\end{array}$ & \\
\hline $\begin{array}{l}\text { Stenotic length } \\
(\mathrm{mm})\end{array}$ & $\begin{array}{l}\text { Range } 4-12.3 \text {, mean } \\
7.7 \pm 2.0\end{array}$ & \\
\hline $\begin{array}{l}\text { Vascular diameter } \\
\text { proximal to the } \\
\text { stenosis }(\mathrm{mm})\end{array}$ & $\begin{array}{l}\text { Range } 1.8-3.5 \text {, mean } \\
2.8 \pm 0.3\end{array}$ & \\
\hline $\begin{array}{l}\text { Post-stent residual } \\
\text { stenosis rate }(\%)\end{array}$ & $\begin{array}{l}\text { Range } 15 \%-35 \% \text {, } \\
\text { mean } 22.8 \pm 4.8 \%\end{array}$ & \\
\hline Stent length (mm) & $\begin{array}{l}4.5 \times 14: 36(58.1 \%) \\
4.5 \times 22: 26(41.9 \%)\end{array}$ & \\
\hline $\begin{array}{l}\mathrm{mRS} \text { score at } \\
\text { discharge }\end{array}$ & $\begin{array}{l}0: 42(70.0 \%) \\
1: 13(21.7 \%) \\
2: 3(5.0 \%) \\
3: 1(1.7 \%) \\
4: 1(1.7 \%)\end{array}$ & \\
\hline
\end{tabular}

TIA: transient ischemic attack, LMA: location, morphology and access, mRS: modified Rankin scoring system.
$4(66.7 \%)$ were immediate residual stenoses after stenting which had a stenosis rate of no smaller than $30 \%$ (Table II). During follow-up, 5 (8.3\%) ischemic events (2 strokes and 3 ITAs) occurred, which were consistent with the vascular lesions in the blood supplying regions. Of the 39 cases without restenoses, DSA indicated that $33(84.6 \%)$ had a residual stenosis rate smaller than the corresponding immediate postoperative stenosis rate.

\section{Risk Factors for ISR}

The results of univariate and multivariate analysis are shown in Table III. Multivariate analysis identified post-stenting residual stenosis rate as a risk factor for ISR ( $\mathrm{P}=0.005$, odds ratio 37.485 95\% Cl 2.955-475.539).

\section{DISCUSSION}

The aim of this study was to evaluate the efficacy and safety of Enterprise stents in the treatment of AIAS. The technical success rate was $100 \%$ and the incidence of perioperative complications was low. The postoperative restenosis rate was $13.3 \%$. A recent study have also used Enterprise stents for AIAS (24), but the present study is the first in a Chinese population, and the results should provide additional important information on the choice of stent for percutaneous transluminal angioplasty and stenting (PTAS).

There are two approaches to treating AIAS, drug therapy and surgical therapy. The Warfarin-Aspirin Symptomatic Intracranial Disease (WASID) trial indicated that the incidence of stroke in the area supplied by the affected vessels in patients with a stenosis rate of $50-99 \%$ who received warfarinaspirin therapy was $11 \%$ within 1 year and $14 \%$ within 2 years postoperatively (4). However, a US multi-center, prospective, randomized control study compared the efficacy between extracranial-intracranial arterial bypass and drug therapy on cerebral vascular stenosis and did not prove the efficacy of extracranial-intracranial arterial bypass on ischemic stroke (1). PTAS has been an alternative choice for the treatment of symptomatic AIAS, which has received increasing interest. The incidence of adverse events in PTAS has significantly decreased with technical advances (8).

A thorough preoperative evaluation is vital for the evaluation of any stenting method since intracranial stenting is rather risky (6). In 1998, Mori et al (18) proposed a classification system for intracranial stenosis, which helps predicting the success rate and complications of percutaneous transluminal angiography (PTA). However, Jiang et al (13) thought that it was difficult to precisely evaluate the outcomes of the Mori classification since they believed that access is an important prognostic factor for successful stent-assisted angioplasty. Therefore, they proposed the classification system of location, morphology and access (LMA) and found that the success rate was higher in type I lesion than in type III and type II + III lesions. Indeed, of the 62 lesions in the present study, 60 were type I + II lesions and only 2 were type III lesions, which probably helped in achieving the high surgical success rate observed here. 

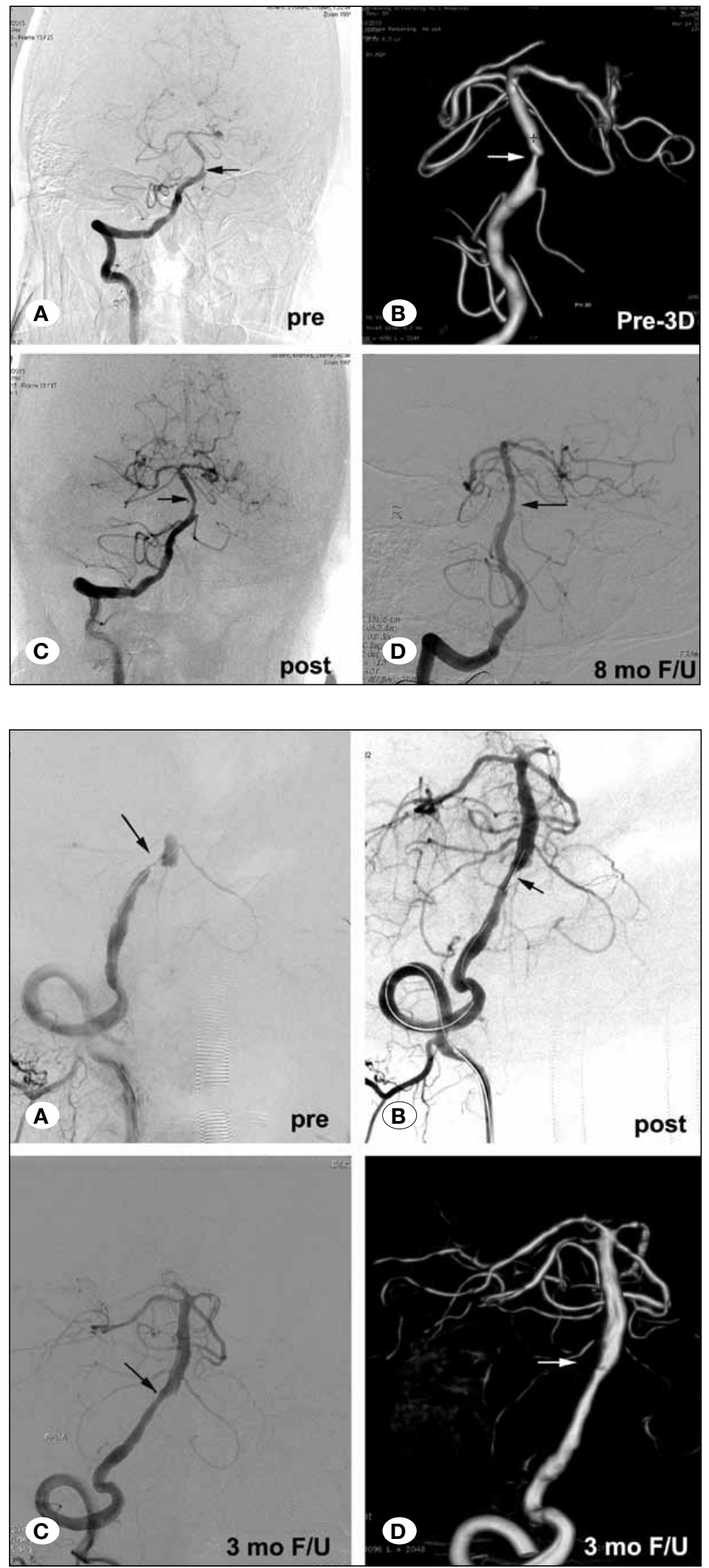

Figure 2: Case 1: High-grade stenosis of the lower segment of the basilar artery. Digital subtraction angiography (DSA) images, A) Stenosis of the lower segments of basilar artery - preoperative image B) preoperative 3D image, C) Angiography after balloon dilation immediately after Enterprise stenting, D) Reexaminations of DSA 8 months postoperatively during follow-up.
Figure 3: Case 2: Right vertebral artery high-grade stenosis; Digital subtraction angiography (DSA) images, A) Right vertebral artery stenosis - preoperative anteroposterior image, B) Angiography after balloon dilation immediately after Enterprise stenting, C) Re-angiography 3 months postoperatively during follow-up, D) 3D image during follow-up. 
Wang X. et al: Enterprise Stent for AIAS

Table II: Patients with Postoperative DSA-Confirmed ISR

\begin{tabular}{cccccc}
\hline $\begin{array}{c}\text { Case } \\
\text { number }\end{array}$ & $\begin{array}{c}\text { Sex/Age } \\
\text { (years) }\end{array}$ & $\begin{array}{c}\text { Stenotic } \\
\text { site }\end{array}$ & $\begin{array}{c}\text { Stenotic } \\
\text { length }(\mathbf{m m})\end{array}$ & $\begin{array}{c}\text { Immediate postoperative } \\
\text { residual stenosis rate }\end{array}$ & Symptom \\
\hline 3 & $\mathrm{M} / 45$ & $\mathrm{BA}$ & 6.4 & $35 \%$ & Infarction (1 month after surgery) \\
\hline 6 & $\mathrm{~F} / 48$ & LVA & 12.3 & $32 \%$ & TIA (3 months after surgery) \\
\hline 21 & $\mathrm{M} / 57$ & LICA & 4.0 & $28 \%$ & TIA (1.5 months after surgery) \\
\hline 34 & $\mathrm{M} / 63$ & LVA & 11.6 & $32 \%$ & None (3 months after surgery) \\
\hline 42 & $\mathrm{M} / 64$ & LICA & 8.8 & $23 \%$ & TIA (6 months after surgery) \\
\hline 48 & $\mathrm{M} / 59$ & $\mathrm{BA}$ & 8.4 & $34 \%$ & Infarction (6 months after surgery) \\
\hline
\end{tabular}

BA: basilar artery, LVA: left vertebral artery, LICA: left internal carotid artery, DSA: digital subtraction angiography; TIA: transient ischemic attack; ISR: in-stent restenosis.

Table III: Analysis of Risk Factors for In-Stent Restenosis (ISR) ( $\mathrm{n}=45)$

\begin{tabular}{lcc|cc}
\hline \multirow{2}{*}{ Risk factors } & \multicolumn{2}{c|}{ Univariate } & \multicolumn{2}{c}{ Multivariate } \\
\cline { 2 - 5 } & P-value & Odds ratio (95\%Cl) & P-value & Odds ratio (95\%Cl) \\
\hline Age & 0.557 & $0.967(0.863-1.082)$ & 0.311 & $0.935(0.821-1.065)$ \\
\hline Stenotic length & 0.304 & $2.588(0.423-15.840$ & 0.151 & $6.234(0.512-75.905)$ \\
\hline Post-stenting residual stenosis rate & 0.005 & $17.5(2.398-127.736)$ & 0.005 & $37.485(2.955-475.539)$ \\
\hline
\end{tabular}

Cl: confidence interval.
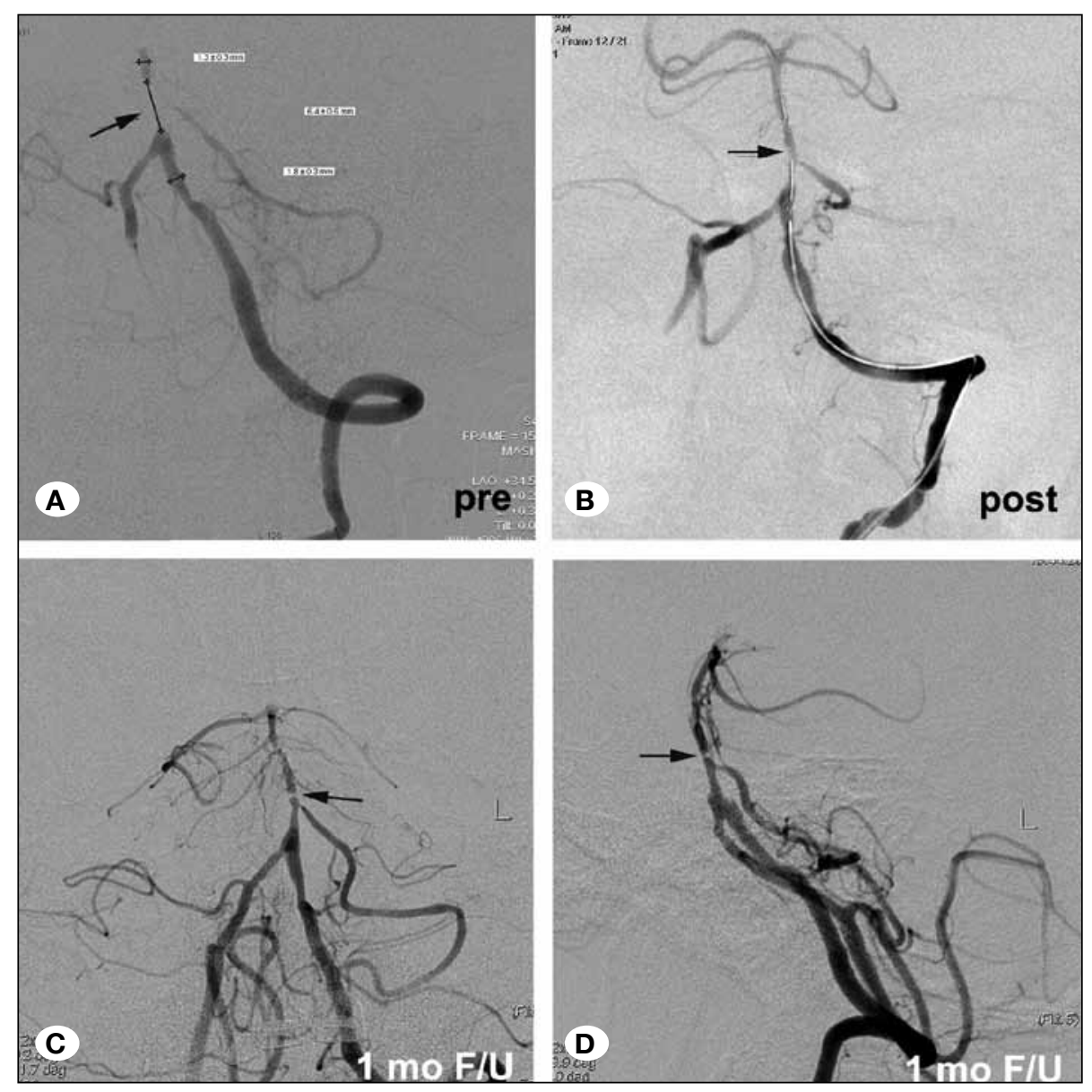

Figure 4: Case 3: High-grade stenosis of the lower segment of the basilar artery. Digital subtraction angiography (DSA) images, A) Stenosis of the lower segment of the basilar artery - preoperative image, B) Angiography after balloon dilation immediately after Enterprise stenting, C, D) Re-angiography 1 month postoperatively during follow-up. DSAconfirmed in-stent restenosis (ISR) (arrow). 
Although techniques are constantly improving, adverse events still occur during and after stenting for AIAS. In a study by Park et al (19), the incidence of adverse events were significantly lower in patients receiving self-expendable stents compared with those receiving balloon-expendable stents. Indeed, self-expandable stents reduce the risk of injury to the artery (7). In the INTRASTENT study, the risk of hemorrhage was relatively high when treating middle cerebral artery stenosis, probably due to the fact that it is relatively difficult to deliver the wire in ultraselection, increasing the risk of damaging the arteries (16). Both the Enterprise and the Wingspan stent are self-expandable stents. Krischek et al (15) have shown that the Enterprise stent has a better flexibility and is easier to deliver than the Wingspan stent, reducing the risk of damaging the arteries. This could explain, at least in part, the high technical success rate of $100 \%$ observed in the present study. In addition, only 5 (8.3\%) patients had perioperative complications and the mortality rate within 30 days was $0 \%$, which was lower than the results of the SAMMPRIS trial (5). The thorough preoperative evaluation and steady control of intraand postoperative blood pressure could explain the absence of cases with reperfusion hemorrhage in the present study. Although preoperative dual antiplatelet therapy was used in all patients using aspirin and clopidogrel, temporary in-stent thrombosis still occurred in one patient intraoperatively and two patients suffered from stroke within 30 days. The patient with in-stent thrombosis was free from bleeding tendencies before the operation, and received the complete anti-platelet regimen of clopidogrel $75 \mathrm{mg} / \mathrm{d}$ and aspirin $300 \mathrm{mg} / \mathrm{d}$. The thrombus disappeared using immediate $400,000 \mathrm{U}$ of urokinase locally delivered using a catheter. The increased number of patients with aspirin and clopidogrel resistance may be one of the reasons for the occurrence of perioperative thrombotic complications (21). Therefore, preoperative monitoring of the patient's response to antiplatelet drugs should be considered as a routine investigation for patients with AIAS who are to receive stent-assisted angioplasty. However, there is a lack of studies about the individual anti-platelet regimens before stenting. Studies should be performed to clarify this issue.

At present, a high restenosis rate has been one of the major adverse events in stent-assisted angioplasty of AIAS, while the benefit a patient achieves with stent-assisted angioplasty is decided by the consistency of the recanalization. Therefore, reduction of ISR has been the focus of attention. A recent systematic review (8) strongly suggests that the post-stenting restenosis rate was $13.8 \%$ in patients with balloon expandable stents and $17.4 \%$ in those with self-expanding stents, while the post-stenting restenosis rate of the Wingspan stent was between $7.5 \%$ and $31.2 \%(3,23)$. Vajda et al $(24)$ believed that the incidence of in-stent restenosis might be underestimated, because in most of the studies only symptomatic patients were followed up angiographically and those who were asymptomatic but with intimal hyperplasia were not followed up. Vajda et al (24) treated 189 patients with AIAS (with 209 lesions) using the Enterprise stent, and reached a DSA followup rate of $83 \%$; they found that the restenosis rate was $24.7 \%$, lower rate than that of Wingspan (31.2\%). Turk et al (23) have found that more ISR occurred with anterior circulation lesions, especially those involving the supraclinoid segment, in younger patients with Wingspan stents. An ISR is defined as a post-stenting stenosis rate $>50 \%$. Theoretically, the higher the residual stenosis rate, the higher risk is for ISR. Yue et al (25) showed that ISR rate in nonresidual $(\leq 30 \%)$ and residual (>30\%) stenosis groups was $17.0 \%$ and $45.5 \%$, respectively. Therefore, residual stenosis is an independent risk factor for ISR. In the present study, 4 (66.7\%) of the 6 patients with ISR had lesions with an immediate postoperative residual stenosis $\geq 30 \%$. The multivariate analysis presented here also revealed that residual stenosis was a risk factor for ISR.

Intimal hyperplasia is the main reason for ISR, since the overdilated vessels may tear the plaques and intima, resulting in hyperplasia of the endothelial and smooth muscle cells. Shin et al (22) found that rapid balloon inflation and longer lengths of stenosis were independent risk factors for ISR using the Wingspan stent. In the present study, we tried our best to use $80 \%$ of the diameters of the normal vessels proximal to the lesions as selection criteria for the balloon sizes. Additionally, as well as controlling the final pressure at a level of $<10$ atm, we also abandoned the post-balloon treatments to avoid intimal injuries and ISR caused by rapid balloon inflation or over-dilation.

In the present study, 6 (13.3\%) of the 45 lesions followed up by DAS had ISR 6 months postoperatively, including 5 symptomatic ISR and 1 asymptomatic intimal hyperplasia, which was lower than the rates reported by the US Multicenter Wingspan Registry (26) and Vajda et al (24). The ISR rate was $20 \%$ for anterior circulation lesions and $11.4 \%$ for posterior circulation lesions. Therefore, the high overall lesion proportion of posterior circulation lesions (which was $77.4 \%$ ) might be a reason for the low overall ISR rate. The Enterprise stent is a self-expanding stent with less radial strength and no plaque cutting, with little stimulation of the intima after stenting, effectively reducing the ISR rate. Moreover, in the 39 lesions without ISR, $33(84.6 \%)$ had a residual stenosis rate smaller than the corresponding immediate postoperative stenosis rate, indicating that consistent post-stenting and low radial strength of the Enterprise stent contributed to the gradual restoration of the stenotic vessels.

\section{- LIMITATIONS}

The retrospective nature of this study resulted in some unavoidable limitations. The Enterprise stent needs to be fully and carefully evaluated using a randomized controlled clinical trial. Until then, retrospective studies like the present study must be relied upon to provide information to surgeons on methods for treating AIAS. Although this study demonstrated a trend towards a higher risk of IRS in patients with anterior circulation lesions, we could not verify it through statistical analyses due to the small sample size. The follow-up duration in this study was rather short. Therefore, a study with a longterm systematic DSA and clinical follow-up is required to more accurately reveal the pathological changes and clinical efficacies of the Enterprise stent. 


\section{CONCLUSION}

With a high technical success rate and low perioperative complication rate, the use of the Enterprise stent in treating AIAS was shown to be safe and efficient in this specific population of AIAS patients. Our results strongly suggested that the ISR rate in Enterprise stenting was lower than most of the currently reported ISR rates in self-expanding stenting.

\section{- REFERENCES}

1. [No authors listed] Failure of extracranial-intracranial arterial bypass to reduce the risk of ischemic stroke. Results of an international randomized trial. The EC/IC Bypass Study Group. N Engl J Med 313:1191-1200,1985

2. Al Hasan M, Murugan R: Stenting versus aggressive medical therapy for intracranial arterial stenosis: More harm than good. Crit Care 16:310,2012

3. Bose A, Hartmann M, Henkes H, Liu HM, Teng MM, Szikora I, Berlis A, Reul J, Yu SC, Forsting M, Lui M, Lim W, Sit SP: A novel, self-expanding, nitinol stent in medically refractory intracranial atherosclerotic stenoses: The Wingspan study. Stroke 38:15311537,2007

4. Chimowitz MI, Lynn MJ, Howlett-Smith H, Stern BJ, Hertzberg VS, Frankel MR, Levine SR, Chaturvedi S, Kasner SE, Benesch CG, Sila CA, Jovin TG, Romano JG: Comparison of warfarin and aspirin for symptomatic intracranial arterial stenosis. $\mathrm{N}$ Engl $\mathrm{J}$ Med 352:1305-1316,2005

5. Derdeyn CP, Chimowitz MI, Lynn MJ, Fiorella D, Turan TN, Janis LS, Montgomery J, Nizam A, Lane BF, Lutsep HL, Barnwell SL, Waters MF, Hoh BL, Hourihane JM, Levy El, Alexandrov AV, Harrigan MR, Chiu D, Klucznik RP, Clark JM, McDougall CG, Johnson MD, Pride GL, Jr., Lynch JR, Zaidat OO, Rumboldt Z, Cloft $\mathrm{HJ}$ : Aggressive medical treatment with or without stenting in high-risk patients with intracranial artery stenosis (SAMMPRIS): The final results of a randomised trial. Lancet 383:333-341,2014

6. Fields JD, Liu KC, Barnwell SL, Clark WM, Lutsep HL: Indications and applications of arterial stents for stroke prevention in atherosclerotic intracranial stenosis. Curr Cardiol Rep 12:2028,2010

7. Fiorella D, Levy El, Turk AS, Albuquerque FC, Niemann DB, Aagaard-Kienitz B, Hanel RA, Woo H, Rasmussen PA, Hopkins LN, Masaryk TJ, McDougall CG: US multicenter experience with the wingspan stent system for the treatment of intracranial atheromatous disease: Periprocedural results. Stroke 38:881887,2007

8. Groschel K, Schnaudigel S, Pilgram SM, Wasser K, Kastrup A: A systematic review on outcome after stenting for intracranial atherosclerosis. Stroke 40:e340-347,2009

9. Henkes H, Miloslavski E, Lowens S, Reinartz J, Liebig T, Kuhne $\mathrm{D}$ : Treatment of intracranial atherosclerotic stenoses with balloon dilatation and self-expanding stent deployment (WingSpan). Neuroradiology 47:222-228,2005

10. Huang Q, Liu J, Zhao R, Hong B, Xu Y, Zhao W, Yang P, Li W: The safety and efficacy of stenting in the treatment of complex posterior cerebral artery aneurysms: A seven-case report and literature review. Clin Neuroradiol 23:175-187,2013

11. Huang QH, Wu YF, Shen J, Hong B, Yang PF, Xu Y, Zhao WY, Liu JM: Endovascular treatment of acutely ruptured, wide-necked anterior communicating artery aneurysms using the Enterprise stent. J Clin Neurosci 20:267-271,2013
12. Jia J, Lv X, Liu A, Wu Z, Li Y: Enterprise stent-assisted coiling of wide-necked intracranial aneurysms: Clinical and angiographic follow-up. Interv Neuroradiol 18:426-431,2012

13. Jiang WJ, Wang YJ, Du B, Wang SX, Wang GH, Jin M, Dai JP: Stenting of symptomatic M1 stenosis of middle cerebral artery: An initial experience of 40 patients. Stroke 35:1375-1380,2004

14. Kim ST, Jeong HW, Jeong YG, Heo YJ, Seo JH, Paeng SH: A Selfexpanding Nitinol Stent (Enterprise) for the treatment of widenecked intracranial aneurysms: Angiographic and clinical results in 40 aneurysms. J Cerebrovasc Endovasc Neurosurg 15:299306,2013

15. Krischek O, Miloslavski E, Fischer S, Shrivastava S, Henkes $\mathrm{H}$ : A comparison of functional and physical properties of selfexpanding intracranial stents [Neuroform3, Wingspan, Solitaire, Leo+, Enterprise]. Minim Invasive Neurosurg 54:21-28,2011

16. Kurre W, Berkefeld J, Brassel F, Bruning R, Eckert B, Kamek S, Klein GE, Knauth M, Liebig T, Maskova J, Mucha D, NeumannHaefelin T, Pilgram-Pastor S, Sitzer M, Sonnberger M, Tietke M, Trenkler J, Turowski B, Group IS: In-hospital complication rates after stent treatment of 388 symptomatic intracranial stenoses: Results from the INTRASTENT multicentric registry. Stroke 41:494-498,2010

17. Lv X, Li Y, Xinjian Y, Jiang C, Wu Z: Results of endovascular treatment for intracranial wide-necked saccular and dissecting aneurysms using the Enterprise stent: A single center experience. Eur J Radiol 81:1179-1183,2012

18. Mori T, Fukuoka M, Kazita K, Mori K: Follow-up study after intracranial percutaneous transluminal cerebral balloon angioplasty. AJNR Am J Neuroradiol 19:1525-1533,1998

19. Park S, Kim JH, Kwak JK, Baek HJ, Kim BH, Lee DG, Lee DH, Kim JS, Suh DC: Intracranial stenting for severe symptomatic stenosis: Self-expandable versus balloon-expandable stents. Interv Neuroradiol 19:276-282,2013

20. Peng T, Qian Z, Liu A, Li Y, Jiang C, Wu Z: Progressive occlusion of enterprise stent-assisted coiling of ruptured wide-necked intracranial aneurysms and related factors on angiographic follow-up: A single-center experience with 468 patients. PLoS One 9:e92407,2014

21. Prabhakaran S, Wells KR, Lee VH, Flaherty CA, Lopes DK: Prevalence and risk factors for aspirin and clopidogrel resistance in cerebrovascular stenting. AJNR Am J Neuroradiol 29:281285,2008

22. Shin YS, Kim BM, Suh SH, Jeon P, Kim DJ, Kim DI, Kim BS, Kim $\mathrm{KH}$, Heo JH, Nam HS, Kim YD: Wingspan stenting for intracranial atherosclerotic stenosis: Clinical outcomes and risk factors for instent restenosis. Neurosurgery 72:596-604; discussion 604,2013

23. Turk AS, Levy El, Albuquerque FC, Pride GL Jr, Woo $\mathrm{H}$, Welch BG, Niemann DB, Purdy PD, Aagaard-Kienitz B, Rasmussen PA, Hopkins LN, Masaryk TJ, McDougall CG, Fiorella D: Influence of patient age and stenosis location on wingspan in-stent restenosis. AJNR Am J Neuroradiol 29:23-27,2008

24. Vajda Z, Schmid E, Guthe T, Klotzsch C, Lindner A, Niehaus L, Sperber W, Peters J, Arnold G, Bazner H, Henkes H: The modified Bose method for the endovascular treatment of intracranial atherosclerotic arterial stenoses using the Enterprise stent. Neurosurgery 70:91-101; discussion 101,2012

25. Yue X, Xi G, Lu T, Xu G, Liu W, Zhang R, Yin Q, Liu X: Influence of residual stenosis on clinical outcome and restenosis after middle cerebral artery stenting. Cardiovasc Intervent Radiol 34:744750,2011

26. Zaidat OO, Klucznik R, Alexander MJ, Chaloupka J, Lutsep H, Barnwell S, Mawad M, Lane B, Lynn MJ, Chimowitz M: The NIH registry on use of the Wingspan stent for symptomatic $70-99 \%$ intracranial arterial stenosis. Neurology 70:1518-1524,2008 